\title{
PTU-116 $九$ SUBSTANTIAL CHEMOPREVENTATIVE EFFECT OF PIROXICAM IN MIN MICE INDEPENDENT OF PEROXISOME PROLIFERATOR ACTIVATED RECEPTOR ALPHA
}

doi:10.1136/gut.2011.239301.244

K M Mccartney, ${ }^{*}$ A Bennett, C Hawkey University of Nottingham, Nottingham, UK

Introduction Non-steroidalanti-inflammatorydrugs (NSAIDs) have been shown to have chemopreventative properties against the development of colon polyps and cancer. We have previously shown that peroxisome proliferator activated receptor (PPAR) - alpha also acts to constrain polyp development in $\mathrm{APC}^{\mathrm{Mint}+-}$ mice. As both eicosanoids and NSAIDs are ligands for PPAR $\alpha$ we investigated the hypothesis that the effects of NSAIDs may be mediated through activation of PPAR $\alpha$ by comparing the effect of the Cox $1 / 2$ inhibitor piroxicam in $\mathrm{APC}^{\mathrm{Min}+/-} \mathrm{PPAR}^{+/+}$mice and $\mathrm{APC}^{\mathrm{Min}+/-} \mathrm{PPAR}^{-/-}$mice.

Aims \& Hypothesis The effect of genotype and piroxicam treatment on longevity, colon and small bowel polyp number and area were investigated. We hypothesise that piroxicam may be prolonging longevity in Min mice due to inhibition of Cox enzyme activity and a resultant activation of PPAR $\alpha$ due to altered eicosanoid metabolism; a reduction in the number of polyps in the small and large bowel will result, inhibiting development of classic Min phenotype (anaemia, white paw and weight loss).

Methods Min mice of PPAR $\alpha^{+/+}$or PPAR $\alpha^{-/-}$genotype were fed standard chow (+ piroxicam $100 \mathrm{ppm}$ or control). Mice were culled if they showed signs of white paw, weight loss $>15 \%$ or tumour-induced prolapse, or at 1 year old if they 
remained healthy. Large and small bowel tissue was removed, flushed and analysed for polyp number and area.

Results Mean age of death in PPAR ${ }^{-1-}$ control mice $(n=22)$ was 22.31 \pm 1.20 (SEM) weeks and 47.67 \pm 1.69 (SEM) weeks in piroxicam treated mice $(\mathrm{n}=23, \mathrm{p}<0.0001), \mathrm{PPAR}^{+/+}$control mice $(\mathrm{n}=22)$ was $24.21 \pm 0.67$ (SEM) weeks and $52.23 \pm 0.37$ (SEM) weeks in piroxicam treated mice $(n=23, p<0.0001)$

The number of polyps in the mouse colon reduced significantly in piroxicam treated mice (age corrected). $\mathrm{PPAR}^{-/-}$control $(\mathrm{n}=18)$ versus $\mathrm{PPAR}^{-/-}$piroxicam $(\mathrm{n}=18, \mathrm{p}=0.028), \mathrm{PPAR}^{+/+}$control $(n=18)$ versus PPAR $^{+/+}$piroxicam $(n=18, p=0.0048)$ There was no significant difference in total polyp area (age corrected). The number of polyps in the small bowel reduced significantly in piroxicam treated mice (age corrected). $\mathrm{PPAR}^{-/}$control $(\mathrm{n}=13)$ versus $\mathrm{PPAR}^{-/-}$piroxicam $(\mathrm{n}=10, \mathrm{p}=0.0001), \mathrm{PPAR}^{+/+}$ control $(n=11)$ versus PPAR $^{+/+}$piroxicam $(n=11, p=0.0004)$ Total polyp area was significantly reduced in piroxicam treated mice (age corrected). $\mathrm{PPAR}^{-/}$control versus $\mathrm{PPAR}^{-/}$piroxicam $\mathrm{p}<0.0001, \mathrm{PPAR}^{+/+}$control versus $\mathrm{PPAR}^{+/+}$piroxicam $\mathrm{p}<0.0001$. Total polyp area (age corrected) was lower in $\mathrm{PPAR}^{+/+}$control mice than in PPAR ${ }^{-1-}$ control mice $(\mathrm{p}=0.0489)$.

Conclusion Piroxicam at 100 ppm results in substantial prolongation of life, to an age greater than previously reported for Min mice. PPAR $\alpha$ status may influence small bowel polyp area but has minimal impact on the effect of piroxicam overall.

Competing interests None.

Keywords cox enzymes, NSAIDs, peroxisome proliferator activated receptor. 